\title{
A ATUAÇÂO DO PSICOPEDAGOGO COM A CRIANÇA COM TRANSTORNO DO ESPECTRO AUTISTA
}

\author{
Solange Rodrigues Silva ${ }^{1}$ \\ UNIVAP- Universidade do Vale do Paraíba \\ Silvia Regina Frate Ruivo ${ }^{2}$ \\ UNIVAP - Universidade do Vale do Paraíba
}

\section{RESUMO}

O objetivo deste trabalho é disponibilizar informações sobre as características do Transtorno do Espectro Autista e possibilidades de intervenções psicopedagógicas. Este documento se fundamentou em pesquisa bibliográfica e teve por principais referências Keinert (2017), Rodrigues e Spencer (2010), Cunha (2017) e Teixeira (2016). Pode-se concluir que a importância do psicopedagogo, independente de sua atuação, na clínica ou em uma instituição, é conhecer a criança, a sua capacidade e suas dificuldades. Estabelecer vínculo com a criança com Transtorno do Espectro Autista é essencial, pois é por meio do vínculo que o psicopedagogo obtém resultados em suas intervenções.

Palavra-chave: Autismo, Criança, Intervenções Psicopedagógicas, Vínculo.

\footnotetext{
${ }^{1}$ Solange Rodrigues Silva - Estudante do curso de Pós graduação Lato Sensu em Psicopedagogia Clínica e Institucional da Univap. Professora de educação infantil da Rede Municipal de São José dos Campos. Email: solange.rs@bol.com.br

${ }^{2}$ Silvia Regina Frate Ruivo - Professora do curso de Pós-Graduação lato sensu em Psicopedagogia Clínica e Institucional da UNIVAP. Psicóloga especialista em neuropsicologia e docência do ensino superior. Email: silvia.frate@hotmail.com
} 


\section{PSYCHOPEDAGOGUE'S ACTING WITH CHILD WITH AUTISM SPECTRUM}

\section{ABSTRACT}

The objective of this work is to provide information about the characteristics of Autism Spectrum Disorder and possibilities of psychopedagogical interventions. This article was based on bibliographical research and had as main references Keinert (2017), Rodrigues and Spencer (2010), Cunha (2017) and Teixeira (2016). It can be concluded that the importance of psychopedagogues, regardless the clinic or in an institution's proceeding, is to comprehend that child, his capacity and his difficulties. To get a bond with the child with Autism Spectrum Disorder is the second important toppic, because it is through the link that the psychopedagogues will obtain good results in their interventions.

Keywords: Autism, Child, Psychopedagogical Interventions, Bond.

\section{Introdução}

As palestras oferecidas aos profissionais da educação em São José dos Campos e do 1 을 Encontro de Educadores em São José dos Campos, cursos e worshops on line do Instituto Neurosaber e Child Behavior Institute of Miami (CBI of Miami) serviram de inspiração e auxiliaram na compreensão do desenvolvimento e da aprendizagem das crianças de modo geral. Porém, os conhecimentos eram insuficientes ao utiliza-los com crianças com Transtorno do Espectro Autista das instituições educacionais que trabalhava, o que motivou o aprofundamento do tema por meio de pesquisa.

A criança com Transtorno do Espectro Autista (TEA), tem prejuízo na socialização, na linguagem e comportamentos repetitivos ou estereotipados ${ }^{1}$. Já a atuação do psicopedagogo relaciona-se com o desenvolvimento da aprendizagem. Compete a este profissional estar atento às dificuldades de aprendizagem das crianças, em especial, àquelas com transtornos de desenvolvimento ou síndromes, visando o aprimoramento do seu desenvolvimento.

Diante do que foi relatado, questiona-se: Como o psicopedagogo pode promover o desenvolvimento e a aprendizagem da criança com TEA? O objetivo deste artigo foi evidenciar a atuação do psicopedagogo com crianças com TEA e abordar intervenções psicopedagógicas nesse processo.

Para a elaboração deste artigo, foi realizada uma pesquisa exploratória no Google Acadêmico sobre os artigos elaborados entre 2016 e 2019 com as palavras chaves "a atuação do psicopedagogo com crianças com transtorno do espectro autista" e obteve-se 1380 resultados. Ao analisá-los, apenas 8 documentos eram referentes à atuação do psicopedagogo com crianças com autismo: três tratavam da relação do psicopedagogo e a inclusão, um abordava o tema família e a psicopedagogia e quatro eram relacionados à avaliação e ferramentas psicopedagógicas. Mesmo estes artigos inferirem o assunto tratado nesta pesquisa, nenhum destes foi utilizado pois não contemplavam o direcionamento desejado para a explanação do tema. 
A metodologia para a elaboração deste artigo foi pesquisa bibliográfica com base nas literaturas de Keinert (2017) é psicóloga com especialização em Psicologia Clínica e Escolar e pós-graduação em Psicologia, abordou as características das crianças com TEA e intervenções.

Rodrigues e Spencer (2010) são respectivamente, pedagogo especialista em psicopedagogia, e a coautora é pedagoga com especialização em Educação Especial e psicopedagogia, Mestrado em Educação, Doutorado em Educação, Pós- Doutorado em Psicologia da Educação. Cunha (2017), é professor da educação básica e ensino superior, psicopedagogo, pesquisador na área educacional e Doutor em Educação. Estes autores enfatizaram sobre as características da criança com TEA e sobre as intervenções psicopedagógicas.

E Teixeira (2016), que é palestrante, médico psiquiatra, com pós graduação em Intervenções Escolares no Autismo, em Dependência Química e em Saúde Mental e Mestre em Educação citou sobre as características da criança com TEA e as intervenções para o tratamento.

Este artigo está dividido em três seções, na primeira foram abordadas as principais características da criança com autismo; a segunda abordou o vínculo entre a criança com Transtorno do Espectro Autista e o psicopedagogo, e a terceira versou sobre as atuações psicopedagógicas com a criança com Transtorno do Espectro Autista e modelos de intervenção.

\section{O Transtorno Do Espectro Autista}

De acordo com Cunha (2017), no início do século passado, precisamente em 1911, o psiquiatra Eugene Bleuler já utilizava o conceito autismo para pacientes que apresentavam comprometimento na comunicação, na interação social e que tinham atividades restrito-repetitivas. Em 1943, o psiquiatra Leo Kanner publicou pesquisas realizadas com crianças que apresentavam inabilidade de relacionamento interpessoal, atraso no desenvolvimento da fala e dificuldades motoras. Ele constatou o surgimento de um distúrbio autístico do contato afetivo e descreveu o autismo como um transtorno que se firma nos primeiros anos de vida da criança. Em 1944, o pediatra Hans Asperger desenvolveu uma tese na qual descrevia comportamentos de crianças com três anos de idade, com comportamentos semelhantes aos descritos por Kanner, porém destacou que as crianças observadas por ele apresentavam uma inteligência superior, aptidão para lógica e interesses excêntricos.

Teixeira (2016) pondera que as pesquisas da psiquiatra da infância, Dra. Lorna Wing, analisam o Transtorno do Espectro Autista (TEA) em três pilares: prejuízo da socialização, prejuízo na linguagem verbal e não verbal e comportamentos repetitivos ou estereotipados. Este estudo ficou conhecido como a "Tríade de Wing".

A pessoa com TEA possui deficits na comunicação e interação social, tem comportamento, interesse e atividades repetitivas e de padrões restritos. Os sintomas aparecem no início do desenvolvimento da criança. A comunicação da criança com TEA é qualificada em três níveis de gravidade:

Nível 1 - Exige apoio: a criança tem dificuldades notórias em sua comunicação quando está sem apoio, para permitir uma interação social.

Nível 2 - Exige apoio substancial: a criança tem dificuldades na comunicação verbal e não verbal, não obtém sucesso ainda que a iniciativa parta do outro. 
Nível 3 - Exige apoio muito substancial: a criança tem dificuldades na comunicação verbal e não verbal com prejuízo de funcionamento. Tem limitações para iniciar uma interação social, conforme esclarece o DSM $5^{2}$ (2014).

A abstração e codificação são necessárias para que a comunicação social ocorra, porém a comunicação da criança com TEA é literal e desprovida de símbolos, o que compromete a sua interação social mesmo sendo do nível 1 . É comum a ecolalia ${ }^{3}$, tanto a imediata como a tardia, conforme explica Cunha (2017).

Para Keinert (2017), as crianças pequenas com TEA apresentam deficits na habilidade de se envolver com as pessoas e compartilhar ideias e sentimentos, podem demonstrar pouca ou ausência de imitação dos outros, pequena ou nenhuma capacidade de iniciar interações sociais e compartilhar emoções. Assim, mesmo que a criança com TEA saiba pronunciar as palavras de forma convencional e que tenha inteligência normal ou até acima do normal, pode ter dificuldades para se comunicar socialmente, interagir com autonomia e ter flexibilidade de atividade.

A autora salienta que a criança com TEA não verbal, em relação às pessoas da cultura na qual está inserida, faz uso reduzido ou atípico de contato visual, gestos, expressões faciais, orientação corporal ou entonação da fala, ou não os faz. Enquanto que a criança típica em processo de desenvolvimento da fala tende a olhar para o outro e apontar o que deseja, a criança com TEA não aponta, mas utiliza o braço ou a mão de outra pessoa como ferramenta para pegar algo que deseja.

Assumpção Jr. e Kuczanski, (2015) relatam que Baron-Cohen e Frith propõem que a Teoria Cognitiva, conhecida também como Teoria da Mente, consiste na inabilidade que a criança com TEA tem em compreender os estados mentais do outro, como dificuldade em perceber crenças, intenções, emoções e conceitos de outra pessoa. Porém, a criança com TEA pode ter um deficit nas suas funções executivas ${ }^{4}$, o que pode gerar inflexibilidade mental, dificuldades em manter a atenção dirigida, em planejamento estratégico e raciocínio.

As características sensoriais irregulares podem estar presentes em crianças com Transtorno do Espectro Autista. Elas podem apresentar hipo ou hipersensibilidade a estímulos visuais, olfativos, auditivos, gustativos e táteis, o que pode explicar a reação de crianças com TEA em ignorar estímulos visuais, pessoas e objetos, e fixar-se em detalhes de um objeto, de uma luz ou nas mãos. Estas crianças podem oscilar quanto sensibilidade a dor e a temperatura, demonstrar uma irritabilidade a diferentes texturas e ao contato físico e ter preferências por gostos ou comer rapidamente sem diferenciar sabores, ressaltam Rodrigues e Spencer (2010).

A criança com TEA pode girar a cabeça com movimentos rápidos ou balançar o corpo de um lado para outro como uma defesa orgânica para compensar as dificuldades na compreensão dos estímulos sensoriais, que são as estereotipias. Elas têm a função de regulação sensorial ou busca de sensação física de prazer. As mais conhecidas são flapping (movimentos de balançar as mãos), rocking (mover o tronco para frente e para trás), andar nas pontas dos pés, movimentar as mãos em frente ao rosto, girar no seu próprio eixo, observar objetos que giram ou sem motivo aparente ou ecolalia, conforme explicam Rodrigues e Spencer (2010) bem como Teixeira (2016).

DSM 5 é o Manual de Diagnóstico e Estatístico de Transtornos Mentais 5a edição.

Ecolalia: Consiste na repetição mecânica de palavras ou frases. Ela pode ser imediata, ou tardia quando a criança, por exemplo, repete por várias vezes o mesmo diálogo que ouviu de um programa de televisão (CUNHA, 2017, p. 27 e 41).

${ }^{4}$ Funções executivas: "[...] as funções executivas são parte de um sistema que atua na capacidade de supervisionar toda a hierarquia de processamento cerebral e abrange habilidades necessárias para efetuar comportamentos dirigidos e com propósito [...]" (ASSUNPÇÃO JR., 2015, p. 112). 
Rodrigues e Spencer (2010) salientam que essas características devem ser consideradas caso a caso. Quanto mais cedo a criança for inserida em um ambiente que estimule seu desenvolvimento, haverá a possibilidade dos sintomas diminuírem e a criança ter resultados mais rápidos e positivos.

Os profissionais apropriados para diagnosticar o TEA são o psiquiatra especialista na infância e adolescência ou neuropediatra, conforme esclarece Teixeira (2016). Porém, é importante que outros especialistas participem do processo de diagnóstico, de modo a colaborar de acordo com a sua área de atuação.

\section{A Construção de Vínculo da Criança Com Transtorno de Espectro Autista}

Conforme citado na seção 2, a criança com TEA possui dificuldade em interagir e estabelecer vínculo e, de acordo com cada nível, comunicar-se com ela pode ser um desafio, o que compromete o aprendizado e o desenvolvimento desta criança. É a partir do vínculo estabelecido que a criança potencializará sua interação com o meio e, consequentemente, e sua aprendizagem. Portanto, ao iniciar um atendimento, é necessário que o psicopedagogo e a família estabeleçam um vínculo afetivo sólido com a criança, para possibilitar uma intervenção pautada na interação.

Nesse sentido, Ribeiro (2014) destaca o modelo DIR - Floortime que aborda o vínculo e a interação entre a criança com TEA e um adulto.

O modelo DIR - Developmental, Individual Difference, Relationship-Based, é baseado no desenvolvimento, nas diferenças individuais e na relação com o outro. Ele foi criado no início dos anos 90 por Stanley Greenspan e Serena Wieder os quais partem da necessidade de auxílio às crianças a atingirem o seu potencial. $O$ objetivo do modelo é que a criança realize interações e desenvolva base para seu desenvolvimento social, emocional e intelectual, conforme descreve Ribeiro (2014).

De acordo com a pesquisadora, este modelo se caracteriza pelo adulto começar a interagir com a criança com TEA a partir do interesse dela, por exemplo, se é uma criança que se interessa por dinossauros, o adulto pode brincar imitando como seria o som de um dinossauro, ou perguntar sobre as espécies de dinossauro. Para a realização deste modelo é essencial que o adulto conheça as preferências da criança com TEA para que ela se interesse pela proposta. $O$ modelo DIR permite ao psicopedagogo capacitado ou à família criar meios para que a criança com TEA interaja com o mundo real.

Ribeiro (2014) assevera que, como parte do modelo DIR, destaca-se a abordagem Floortime, que foi desenvolvida por Greenspan, e é realizada com a criança e um adulto no chão com atividades do interesse da criança. As atividades podem partir de um brinquedo que a criança goste como um carrinho, um instrumento musical ou um livro, por exemplo. $O$ objetivo é que o adulto e a criança compartilhem do mesmo objeto ou utilizem objetos iguais. A autora explica que esta abordagem pode ser utilizada pela família, quando capacitada, já que é ela que passa o maior tempo com a criança com TEA. As intervenções não podem ultrapassar 20 minutos.

O principal desses pontos é o brincar como alicerce do desenvolvimento infantil, uma vez que o Floortime refere como base de sua prática as interações espontâneas que ocorrem durante brincadeiras, reconhecendo que a evolução no desenvolvimento é maior quando acontece de forma concomitante a uma atividade prazerosa para a criança e potencializando assim a efetividade do tratamento. [...] (RIBEIRO, 2014, p. 404). 
Neste contexto, destaca-se o papel do psicopedagogo na orientação à família quanto a técnica utilizada.

Outro modelo utilizado para estabelecer vínculo com a criança com TEA é o modelo Son-Rise. Este modelo foi criado na década de 70 por Barry Kaufman e Samahria Kaufman após seu filho, Raun Kaufman, ser diagnosticado com TEA de nível grave. O casal percebeu que Raun precisava de intervenções terapêuticas para desenvolver sua capacidade e começaram a realizar intervenções na própria casa.

Oliveira (2015) explica que este modelo é desenvolvido apenas com a criança, o adulto com quem irá interagir e os brinquedos e atividades que lhe despertem o interesse, para motivar a realização das propostas. O ambiente deve ser de cor neutra e estar livre de distrações para que a criança mantenha a atenção na atividade, no adulto que está com ela e em si mesma. O modelo Son-Rise tem por objetivo mostrar possibilidades de interações sociais, emocionais e cognitivas com a criança com TEA.

De acordo com a autora, tanto o modelo Son-Rise quanto o DIR-Floortime são indicados principalmente para familiares e cuidadores capacitados, por serem as pessoas que permanecem maior tempo com a criança. Embora ambos os modelos apresentem bons resultados, ainda não existe evidência científica.

Em contraponto, Ribeiro (2014) defende que o modelo DIR-Floortime pode ser usado tanto por profissionais quanto familiares e cuidadores capacitados. Da mesma forma, Cunha (2017) corrobora que pais e educadores aprendem a interagir com a criança com TEA com o modelo Son-Rise e que por meio dele se possibilita o desenvolvimento emocional e cognitivo. Assim, recomenda-se ao psicopedagogo um aprofundamento sobre os modelos apresentados, tanto para uso psicopedagógico como para orientar os familiares e cuidadores das crianças com TEA.

Outras atividades que proporcionam o vínculo e a interação que podem ser utilizadas tanto pelo

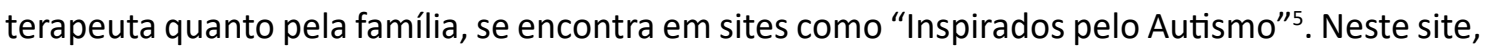
especificamente, encontram-se sugestões de atividades como por exemplo, imitar a criança com TEA de forma paralela a ela com brinquedos iguais ou similares e a partir daí realizar intervenções e direcionar a brincadeira conforme a intencionalidade do adulto. Outras atividades propostas pelo site, que podem despertar a atenção compartilhada e a imitação são: brincadeiras corporais, bolinhas de sabão, músicas e histórias do interesse da criança.

\section{O Psicopedagogo e a Sua Atuação Com Crianças Com Transtorno do Espectro Autista}

De acordo com Bossa (2011), a Psicopedagogia surgiu a partir da necessidade de um profissional que atendesse crianças e adolescentes com problemas de aprendizagem, por meio das áreas limites da psicologia e pedagogia. Mas, para compreender os problemas de aprendizagem, é necessário inicialmente saber como o sujeito aprende. Desta forma, o psicopedagogo se destaca como o profissional que irá investigar como ocorre o aprendizado, bem como atuará de forma preventiva para evitar deficits de aprendizagem. 
Quando falamos de aprendizagem, entendemos que se trata de um processo complexo que, a partir de ocorrências e mudanças no interior de indivíduo, manifesta-se exteriormente, expressando-se por meio de ações cognitivas, emocionais e comportamentais. (CUNHA, 2017, p. 108).

Nesse sentido, o profissional de psicopedagogia se atentará para a necessidade da criança com TEA em sua singularidade. Como já mencionado, a criança com TEA se caracteriza pelos deficits no estabelecimento do vínculo e na interação, o que compromete a aprendizagem e seu desenvolvimento. Portanto, a atuação do psicopedagogo iniciará pelo estabelecimento de vínculo com o aprendente e na orientação para a família e profissionais da educação para que a criança com TEA crie vínculos com as pessoas que façam parte de seu cotidiano, pois ela "[...]aprende nas suas trocas no mundo afetivo e social, ao mesmo tempo em que se torna o seu principal interlocutor na aquisição do conhecimento." (CUNHA, 2017, p. 117).

Ao atender uma criança com TEA, o psicopedagogo prioriza a autonomia da criança, ela deve aprender a realizar atividades de seu cotidiano para que se torne um adulto autônomo. Vale ressaltar a importância da parceria com professores, familiares, cuidadores e outros profissionais que atendem a criança, todos devem estar alinhados ao mesmo objetivo, como explana Cunha (2017).

O artigo 30 da lei Berenice Piana ${ }^{6}$ (lei 12. 764 / 12) defende o direito ao acesso escolar da criança com TEA. No parágrafo único, menciona-se o direito que a criança com TEA tem a um profissional mediador para auxiliá-la, desde que seja comprovada a necessidade do auxílio desse profissional. Para Keinert (2010), o profissional deve auxiliar a criança quando necessário, sem tirar a autonomia dela, para que ela participe dos grupos na sala de aula. Não há inclusão quando a criança interage apenas com o profissional mediador e fica isolada dentro do grupo.

Para Cunha (2017), o currículo escolar deve ser constituído de acordo com as necessidades e possibilidades da criança e com a realidade de sua escola. Cada instituição escolar tem a sua limitação e especificidade, que irá adequar-se às necessidades das crianças que atende. $O$ psicopedagogo deve estar atento quanto à aprendizagem da criança com TEA em sua complexidade e como a instituição escolar pode ampliar o conhecimento da criança ao promover a autonomia e a inclusão.

[...] A escola deve educar, também, para o desenvolvimento da autonomia do aprendente, abrangendo toda a complexidade que há na individualidade de cada um, pois a natureza humana é uma unidade complexa, é um só tempo físico, biológico, psíquico, cultural, social e histórico. Este é um olhar psicopedagógico. (CUNHA, 2017, p. 113).

Cada criança tem uma necessidade diferente da outra e para que o psicopedagogo auxilie a criança em seu desenvolvimento, é necessário que ela seja atendida por outros profissionais (como psicólogos, fonoaudiólogos, terapeuta ocupacional) que possam diminuir ou sanar suas limitações, ressaltam Cunha (2017) e Teixeira (2016).

É preciso que o psicopedagogo conheça as características próprias da criança com TEA na sua singularidade, para que se possa criar vínculo e favorecer a aprendizagem. Ele poderá intervir com atendimentos individuais ou em grupo para oportunizar a inclusão desta criança. Em atendimentos institucionais, é necessário orientar os profissionais da educação para que possam auxiliar a criança com TEA em seu aprendizado.

A lei 12. 764/12 reconhece o autismo como uma deficiência e estende às pessoas com TEA os direitos previstos aos que tem algum tipo de deficiência. Ela foi sancionada no dia 28 de dezembro de 2012 e leva o nome de sua co-autora, Berenice Piana. 
Segundo Teixeira (2016), para a realização do tratamento da criança com TEA, é preciso elaborar um Plano Individual de Tratamento (PIT) de acordo com as necessidades da criança, grau de gravidade e a disponibilidade e adesão da família para que o profissional possa realizar boas intervenções. O PIT consiste em um projeto que o profissional irá elaborar no qual contenham as intervenções necessárias e seus objetivos. No PIT deve constar os modelos e programas de atendimentos e funcionará como um roteiro para o psicopedagogo.

Dos modelos de intervenções utilizados com crianças com TEA, Cunha (2017) e Keinert (2017) destacam:

Picture Exchange Comunication System - (PECS) ou Sistema de Comunicação por Troca de Figuras, que consiste em fichas com figuras que representam palavras, sentimentos, ações e situações. O PECS auxilia na comunicação das crianças com TEA não verbais e favorece o desenvolvimento da comunicação. Após a criança apropriar-se do uso das fichas, ela pode ser estimulada a pedir verbalmente, como por exemplo: dizer "Eu quero" e entregar a ficha com a figura do que deseja. O psicopedagogo pode utilizar deste modelo para que a criança com TEA aprenda a se comunicar com autonomia, e deverá orientar a família e os profissionais da educação que atendem esta criança quanto ao uso do modelo, para que esta exercite a comunicação em diferentes situações de seu cotidiano.

Treatment and Education of Autistic and related Comunication-handicapped Children (TEACCH) ou Tratamento e Educação de Crianças com Autismo e Dificuldades de Comunicação: este tratamento foi desenvolvido na década de 60 pelo Dr. Eric Schopler e colaboradores. Esta abordagem consiste em utilizar recursos visuais como uma sequência de figuras nos ambientes nos quais a criança com TEA frequenta. Como exemplos destacam-se as atividades de uma rotina escolar, procedimentos para utilizar o banheiro e escovar os dentes, conteúdos escolares como o processo de digestão, ciclo da água, atividades físicas. Pode ser utilizado em atendimentos psicopedagógicos clínicos como agenda para situar a criança no tempo e na sequência de atividades, e também ensinar a criança com TEA procedimentos diversos. $\mathrm{O}$ seu objetivo é proporcionar e desenvolver a sua autonomia e o aprendizado, além de favorecer a atenção e concentração, e cabe ao psicopedagogo utilizar de acordo com a necessidade da criança e orientar a família e os profissionais da educação.

Applied Behavior Analysis - ABA ou Análise do Comportamento Aplicado, é utilizado por profissionais capacitadas a utilizar este método ou psicólogos experientes. O ABA consiste em ensinar novas habilidades, corrigir comportamentos inadequados (tais como agressividade, birra), e reforçar comportamentos positivos por meio de recompensa. Nesta abordagem, a repetição é de extrema importância, assim como os registros com o resultado de cada tentativa. Quando a criança apropriar-se do comportamento positivo, deve-se dar a oportunidade para que ela o realize com autonomia e o desenvolva como um hábito. É um modelo utilizado em consultórios psicopedagógicos para desenvolver hábitos de aquisição de aprendizagem, que são necessários para a realização de atividades em instituições escolares.

O psicopedagogo deve estar atento ao desenvolvimento da criança com TEA não apenas durante os atendimentos, mas em sua complexidade como indivíduo. A família da criança necessita de ajuda, apoio e orientações, para auxiliar a criança com TEA fora dos atendimentos, conforme afirma Keinert (2017).

\section{Considerações Finais}

Pode-se concluir que ao iniciar os atendimentos, o profissional de psicopedagogia deve conhecer a criança, suas dificuldades e habilidades. A criança com TEA demanda de uma atenção 
especializada, além do alhar atento. O psicopedagogo deve ser um pesquisador para identificar e auxiliar em suas necessidades.

Estabelecer vínculo e interagir com a criança com TEA é essencial para o seu aprendizado. O psicopedagogo deverá utilizar modelos de intervenções de acordo com as habilidades e dificuldades da criança. Cabe ao profissional de psicopedagogia conhecer e estudar os modelos de intervenções que irá utilizar, e apropriar-se das técnicas disponíveis, estabelecer vínculo afetivo com a criança e, assim, proporcionar à criança, autonomia e aprendizagem. Independente de deficiências, transtornos ou de outras dificuldades, as emoções do aprendente devem ser canalizadas para a aprendizagem.

Conforme Cunha (2017) destaca, o psicopedagogo deve utilizar dos interesses que a criança com TEA possui como ponto de partida para realizar intervenções tanto no consultório quanto nas instituições escolares.

A parceria com outros especialistas e profissionais da educação que atendem a mesma criança é tão importante quanto a parceria com a família para que se possa obter o desenvolvimento integral do aprendente.

Neste contexto, esta pesquisa contempla o questionamento inicial sobre a promoção do desenvolvimento e aprendizagem da criança com TEA, pois abordou estratégias de intervenção que podem ser utilizadas pelo psicopedagogo, bem como sua contribuição na orientação e suporte às famílias.

O profissional de psicopedagogia deve elaborar um Plano Individual de Tratamento de acordo com as necessidades e habilidades da criança e com as possibilidades do ambiente. É preciso que aprimore a prática psicopedagógica por meio de pesquisa constante sobre os modelos de intervenções que podem ser utilizados com a criança com TEA para que a sua atuação seja eficaz.

\section{Referências}

ASSUMPÇÃO JR., Francisco Baptista. Autismo Infantil - Novas Tendências e perspectivas 2a edição. São Paulo: Editora Atheneu, 2015.

CUNHA, Eugênio. Autismo e Inclusão - Psicopedagogia e práticas educativas na escola e na família 7ạ edição. Rio de Janeiro: Wak Editora, 2017.

FIORE-CORREIA, Olivia e Carolina Lampreia. A Conexão Afetiva nas intervenções Desenvolvimentistas para Crianças Autistas. Psicologia, Ciência e Profissão. Brasília. Vol. 32. Número 4. Páginas 926-941. 2012.

GOOGLE ACADÊMICO. A atuação do psicopedagogo com crianças com autismo, São José dos Campos, 2019. Disponível em: <https://scholar.google.com.br/scholar?start =120\&q=interven\%C3\%A7\%C3\%B5es+psicopedag\%C3\%B3gicas+com+crian\%C3\%A7as +com+transtorno+do+espectro+autista\&hl=ptBR\&lr=lang_pt\&as_sdt=1,5\&as_ylo=2016\&as _yhi=2019\&as_vis=1>. Acesso em 7 jul. 2019.

INSTITUIÇÃO INSPIRADOS PELO AUTISMO. Atividades Interativas para pessoas com autismo. Disponivel em: <https://www.inspiradospeloautismo.com.br/a-abordagem/atividadesinterativas-para-pessoas-com-autismo> Acesso em: 10 de abr. de 2019. 
KEINERT, Maria Helena Jansen de Mello. Espectro Autista - O que é? O que fazer? 2 ed. Curitiba: Íthala, 2017.

NASCIMENTO, Maria Inês Corrêa. Manual Diagnóstico e Estatístico de doenças mentais - DSM 5 ed. Porto Alegre: Artmed, 2014.

OLIVEIRA, Joana Maria Sousa Silva. Pertubação do Espetro do Autismo: Sinais de Alerta e Estratégias. 2015. Dissertação (Mestrado na área das Ciências da Educação - Especialização em Educação Especial) - Escola Superior de Educação de Paula Frassinetti de Porto, Porto. 2015. <http://hdl.handle.net/20.500.11796/2213> Acesso em: 19 de abr. de 2019.

RIBEIRO, Luciana de Cássia. Abordagem Floortime no tratamento da criança autista: possibilidades de uso pelo terapeuta ocupacional. Cadernos Brasileiros de Terapia Ocupacional UFSCar. São Carlos. Vol. 22. Número 2. Páginas 399 - 408. 2014. Disponível em < https://doi.org/10.4322/cto.2014.060> Acesso em: 19 de abr. de 2019.

RODRIGUES, Janine Marta Coelho; SPENCER, Eric. A Criança Autista - Um estudo Psicopedagógico. Rio de Janeiro: Wak Editora,2010.

TEIXEIRA, Gustavo. Manual do Autismo. Rio de Janeiro: BestSeller, 2016. 